\title{
EFFECTS OF ZINC POWDER ADDITION TO VILLA GLOSS AND SILKA LUX MARINE ENAMEL PAINTS ON CORROSION RESISTANCE OF MILD STEEL
}

\author{
W. A. Ayoola ${ }^{1,}$, M. A.Bodude ${ }^{2}$, H. Onovo ${ }^{3}$ and A. Oyetunji ${ }^{4}$

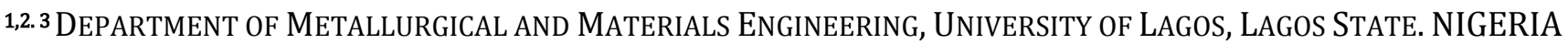 \\ 4 Dept. of Metallurgical and Materials EnG'G, Fed. Univ. of Technology AKure, Ondo State. Nigeria \\ E-mail adresses: ${ }^{1}$ wayoola@unilag.edu.ng, ${ }^{2}$ mbodude@unilag.edu.ng, ${ }^{3}$ honovo@unilag.edu.ng, \\ 4 akinlabioyetunji@yahoo.com
}

\begin{abstract}
The anti-corrosion properties of paints can be optimised when adequate proportion of the paint constituents are used. Effect of zinc powder addition to Villa Gloss and Silka Lux Marine Enamel paints on corrosion resistance of mild steel was studied. Quantitative Analysis and Potentiodynamic Polarisation Technique were used to evaluate the samples. The results indicate that zinc powder addition between 15 and $25 \%$ significantly reduced the corrosion rate. The corrosion rate stabilized at approximately 0.10 mmpy when zinc powder added was above $15 \%$, independent of the exposure time. Potentiodynamic anodic polarization curves of the samples immersed in seawater showed that sample with 25\% zinc powder addition exhibited highest corrosion potential and the least corrosion current density. Microstructural analysis of the samples also revealed the presence of pitting corrosion at the surfaces of the samples and their geometry, volume fraction and distribution vary with the zinc powder addition.
\end{abstract}

Keywords: zinc powder, inhibition efficiency, potentiodynamic, weight loss, corrosion rate, pit corrosion

\section{NOMENCLATURE}

$\mathrm{A}_{1}$ uncoated sample.

$\mathrm{A}_{2} \quad$ sample coated with $10 \mathrm{ml}$ of white paint $+0 \%$ zinc powder.

$\mathrm{A}_{3}$ sample coated with $10 \mathrm{ml}$ of red paint $+0 \%$ zinc powder.

$B_{1}$ sample coated with $10 \mathrm{ml}$ of white paint $+5 \%$ zinc powder.

$\mathrm{B}_{2}$ sample coated with $10 \mathrm{ml}$ of red paint $+5 \%$ zinc powder.

$\mathrm{C}_{1}$ sample coated with $10 \mathrm{ml}$ of white paint $+10 \%$ zinc powder.

$\mathrm{C}_{2}$ sample coated with $10 \mathrm{ml}$ of red paint $+10 \%$ zinc powder.

$\mathrm{D}_{1}$ sample coated with $10 \mathrm{ml}$ of white paint $+15 \%$ zinc powder.

$\mathrm{D}_{2}$ sample coated with $10 \mathrm{ml}$ of red paint $+15 \%$ zinc powder.

$\mathrm{E}_{1}$ sample coated with $10 \mathrm{ml}$ of white paint $+20 \%$ zinc powder.

$\mathrm{E}_{2}$ sample coated with $10 \mathrm{ml}$ of red paint $+20 \%$ zinc powder.

$\mathrm{F}_{1}$ sample coated with $10 \mathrm{ml}$ of white paint $+25 \%$ zinc powder.
$\mathrm{F}_{2}$ sample coated with $10 \mathrm{ml}$ of red paint $+25 \%$ zinc powder.

$\mathrm{C}_{\mathrm{r}} \quad$ corrosion rate (mmpy)

$\mathrm{W}_{\mathrm{t}}$ weight loss (milligrams)

A Surface area of the sample $\left(\mathrm{cm}^{2}\right)$

$\mathrm{T}$ time of exposure of the samples in hour(s)

$\rho$ metal density $\left(\mathrm{g} / \mathrm{cm}^{3}\right)$

$\mathrm{L}$ length of the sample $(\mathrm{cm})$

B breadth of the sample $(\mathrm{cm})$

$\mathrm{T}$ thickness of the sample $(\mathrm{cm})$

\section{INTRODUCTION}

Painting or coating of all kinds are often used to provide interior and exterior decoration, which makes the environment appealing. Painting is a major method of protecting metal surfaces from different types of corrosion and its application is comparatively easy with no limitation on the size of the steelwork or materials that can be treated. Hence, painting of all kinds is very attractive and convenient means of corrosion control. Besides decoration and corrosion prevention purposes, painting or coating of surfaces can also serve purposes such as light reflectivity, camouflaging surfaces and heat absorber $[1,2]$. 
Paintings of steelwork and other surfaces are very useful. Nevertheless, deterioration and degradation of paints set-in over time and thus corrosion of surfaces is inevitable. Commonest among the causes of earlier corrosion are deficient surface preparation[3], insufficient coating thickness $[4,5]$, incorrect formulation of paint by the manufacturer $[6,7]$, inadequate skill of the painter, wrong choice of paints, drastic change in environmental conditions, mechanical or human physical damage.

Incorrect formulation of paint by manufacturer seems to be a major challenge in corrosion prevention [7]. This is because all other causes of corrosion can be corrected prior to paint application but wrong formulation required new production. The principal ingredients of paints are pigments, fillers, co-reactant and surfactant [1]. Each of these ingredients is required in a certain proportion for the formulation and performance properties. The atoms of the ingredients join together to form molecules, which crosslink's with one another, the reactive sites of each of the reacting molecules must align and come within very close proximity to each other for coating. Basically, the main function of the metallic pigments is to form sacrificial metallic oxides with the environment or seawater [8]. However, paints with inadequate metallic pigments corrode earlier and the steel underneath is exposed for chemical attack. For example, when a scratch or a break occurs in a zinc-rich paint film, water and oxygen combine with the metallic zinc. Over time, the zinc particles will corrode away and the paints protective ability will be lost.

Investigation has been conducted to examine the effect of metallic pigments on corrosion control of steels immersed in corrosive media. In the study of Fayomi and Popoola, the electrochemical behaviour and the corrosion properties of $\mathrm{Zn}$ coating on steel substrates by means of Vickers micro hardness and polarization measurements was investigated[9]. Effect of graphite addition on the corrosion resistance and mechanical properties of zinc chromate epoxy paint was evaluated by Mirhabibi et al.[10]. They declared that addition of

graphite decreases the corrosion rate and impact resistance while the resistance against the abrasion increases due to hydrophobic properties of the graphite. In a similar study by Durodola et al. [11] steel substrate was coated with zinc and immersed in seawater and compared with uncoated steel. They concluded that coated steel performed better than uncoated steel substrate. Abdou and Yaser studied the effect of recent three types coatings used in marine ship surfaces for prevention against corrosion. They revealed that coating significantly enhance the corrosion protection of coated sample by $70 \%$ when compared to the uncoated sample[8].In this study, the effect of zinc powder addition on corrosion properties of Villa Gloss and Silka Lux Marine Enamel paints was examined. The objective of this article is to investigate not only the benefit of zinc powder addition to the paints, but also to determine its effect on corrosion resistance of mild steel.

\section{MATERIALS AND METHODS}

\subsection{Materials and Equipment}

The following are the materials used for this study: mild steel, paints (red and white colours), zinc powder, seawater, distilled water, emery papers, ethanol, digital weighing balance, hack saw, laboratory beaker, flask and plastic brush.

The mild steel was obtained from Niger Dock Nigeria PLC, Lagos, Nigeria. The red and white paints were procured from local vendors in Lagos State, Nigeria. The nominal chemical composition of mild steel and paints are given in Tables 1 and 2 respectively. The chemical composition of the corrosive medium (seawater) and zinc powder are presented in Table 3 and Table 4 respectively. Spectrometry analysis (Spectomax LM806-Amatek, USA) was used to obtain the chemical composition of the mild steel and zinc powder. Quantitative analysis with the aid of Atomic Absorption Spectroscopy (Perkin Elmer AAS3100 model, UK) was used to obtain the nominal chemical composition of the semi-liquid paints, shown in Fig. 1 (a).

Table 1: Chemical Composition of the Mild Steel used (Wt \%)

\begin{tabular}{lcccccccccc}
\hline Elements & $\mathrm{C}$ & $\mathrm{Si}$ & $\mathrm{Mn}$ & $\mathrm{P}$ & $\mathrm{S}$ & $\mathrm{Cr}$ & $\mathrm{Mo}$ & $\mathrm{Ni}$ & $\mathrm{Al}$ & $\mathrm{Co}$ \\
\hline Composition(wt. \%) & 0.129 & 0.242 & 1.35 & 0.0148 & 0.0031 & 0.0187 & 0.001 & 0.0015 & 0.03 & 0.004 \\
Elements & $\mathrm{Cu}$ & $\mathrm{Nb}$ & $\mathrm{Ti}$ & $\mathrm{V}$ & $\mathrm{W}$ & $\mathrm{Pb}$ & $\mathrm{Sn}$ & $\mathrm{Mg}$ & $\mathrm{As}$ & $\mathrm{Zr}$ \\
Composition(wt. \%) & 0.008 & 0.004 & 0.001 & 0.0057 & 0.007 & 0.002 & 0.004 & 0.001 & 0.003 & 0.0015 \\
Elements & $\mathrm{Bi}$ & $\mathrm{Ca}$ & $\mathrm{Ce}$ & $\mathrm{Sb}$ & $\mathrm{Se}$ & $\mathrm{Te}$ & $\mathrm{Ta}$ & $\mathrm{B}$ & $\mathrm{Zn}$ & $\mathrm{Fe}$ \\
Composition(wt. \%) & 0.002 & 0.001 & 0.0015 & 0.0025 & 0.0037 & 0.0027 & 0.043 & 0.0014 & 0.003 & 98.1 \\
\hline
\end{tabular}


Table 2: Atomic Absorption Spectrophotometric of the Red and White Paints used

\begin{tabular}{lcc}
\hline Paint types & Zinc (mg/L) & Calcium (mg/L) \\
\hline Villa Gloss (white paint) & 0.2817 & 2.009 \\
Silka Lux Marine Enamel (red paint) & 1.6618 & 24.570 \\
Blank & 0.0010 & 0.001 \\
\hline
\end{tabular}

Table 3: Chemical Composition of Seawater

\begin{tabular}{lllll}
\hline Parameters & Unit & Results & $\begin{array}{l}\text { Maximum Permitted[12], } \\
{[13]}\end{array}$ & Health Effect \\
\hline pH & - & 6.47 & $6.5-8.5$ & None \\
Conductivity & $\mu \mathrm{S} / \mathrm{cm}^{3}$ & 4940.000 & 1000 & None \\
Total hardness & $\mathrm{mg} / \mathrm{L}$ & 150.00 & 150 & None \\
Total alkalinity & $\mathrm{mg} / \mathrm{L}$ & 50.00 & 50 & - \\
Total acidity & $\mathrm{mg} / \mathrm{L}$ & 50.00 & 50 & - \\
Calcium & $\mathrm{mg} / \mathrm{L}$ & 60.12 & 50 & - \\
Magnesium & $\mathrm{mg} / \mathrm{L}$ & 21.84 & 0.20 & Consumer Acceptability \\
Chloride & $\mathrm{mg} / \mathrm{L}$ & 15083.98 & 250 & None \\
Salinity & $\mathrm{mg} / \mathrm{L}$ & 27250.00 & & \\
Copper & $\mathrm{mg} / \mathrm{L}$ & 0.072 & 1 & Gastrointestinal Disorder \\
Iron & $\mathrm{mg} / \mathrm{L}$ & 0.69 & 0.3 & None \\
Zinc & $\mathrm{mg} / \mathrm{L}$ & 0.169 & 3 & Cancer \\
Lead & $\mathrm{mg} / \mathrm{L}$ & 0.09 & 0.01 & Toxic to kidney \\
Cadmium & $\mathrm{mg} / \mathrm{L}$ & 0.002 & 0.003 & Possibly carcinogenic \\
Nickel & $\mathrm{mg} / \mathrm{L}$ & 0.16 & 0.02 & Cancer \\
Chromium & $\mathrm{mg} / \mathrm{L}$ & 0.051 & 0.05 & \\
\hline
\end{tabular}

Table 4: The Nominal Chemical Composition of the Zinc Powder

\begin{tabular}{lllllll}
\hline Elements & $\mathrm{Cd}$ & $\mathrm{Ca}$ & $\mathrm{Fe}$ & $\mathrm{Cu}$ & $\mathrm{Sn}$ & $\mathrm{Zn}$ \\
\hline Compositions (wt. \%) & 0.200 & 4.200 & 0.010 & 0.005 & 0.010 & 95.570 \\
\hline
\end{tabular}

2.2 Preparation of Samples and its Immersion Technique The as-received mild steel was machined into test samples of dimensions of $2.20 \mathrm{~cm}$ by $1.50 \mathrm{~cm}$ by 1.16 $\mathrm{cm}$. The samples were smoothened on emery papers of 80, 150,and 320gritsand later polish to obtain mirror like surface. Then, the samples we rewashed in distilled water with a plastic brush and then soaked in an ethanol for 5 minutes. Subsequently, the samples were allowed to dry for 5 minutes[14]. The test samples were individually designated for easy identification (see Nomenclature).The test samples were then coated sacrificially with two different commercial paints that have varied percentages by weight of zinc powder(see Nomenclature).The final coating thickness of the samples was $20 \mu \mathrm{m}$, which classify the coating process adopted as thin films[15].The initial weight $\left(\mathrm{W}_{1}\right)$ of the sample was taken using a digital weighing scale. Thereafter, equal proportion of analysed corrosive medium of $300 \mathrm{ml}$ was measured out with laboratory beaker and poured into transparent flasks. The samples were then completely immersed in the corrosive medium (see Figure 1b).After every 3-day (72-hour) of immersion, individual sample was brought out of the corrosive medium and then gently and thoroughly cleaned with distilled water and ethanol and then weighed for final weight $\left(\mathrm{W}_{2}\right)$. The weight loss $\left(\mathrm{W}_{\mathrm{t}}\right)$ obtained was then used to calculate the corrosion rate. In all cases, the processes of samples cleaning, washing, drying, weighing were thoroughly and gently carried out - since the data collection largely depend on these processes[16]. To enhance the reliability of the results, each test was repeated twice times.

\subsection{Quantitative Analysis Method}

This work employed a quantitative analysis technique for the determination of the corrosion rate based on the weight loss method. It involved taking the weight loss $\left(\mathrm{W}_{\mathrm{t}}\right)$ of uncoated and coated samples before and after immersion in the corrosive medium. The corrosion rate was calculated accordingto the Equations (I) and (II) [8].

$$
\begin{aligned}
& \text { Corrosion rate, } C_{T}(\text { mmpy }) \\
& =\frac{87.6 \times \text { weight loss }\left(W_{t}\right)}{\operatorname{Area}(A) \times \operatorname{time}(T) \times \operatorname{Density}(\rho)}
\end{aligned}
$$

Where:

Surface area $(A)$

$$
=2[L \times B)+(L \times H)+(B \times H)]
$$

The weight loss was also used to calculate the surface coverage and Inhibition Efficiency according to Equations (3) and (4) respectively after 1800 hours. 

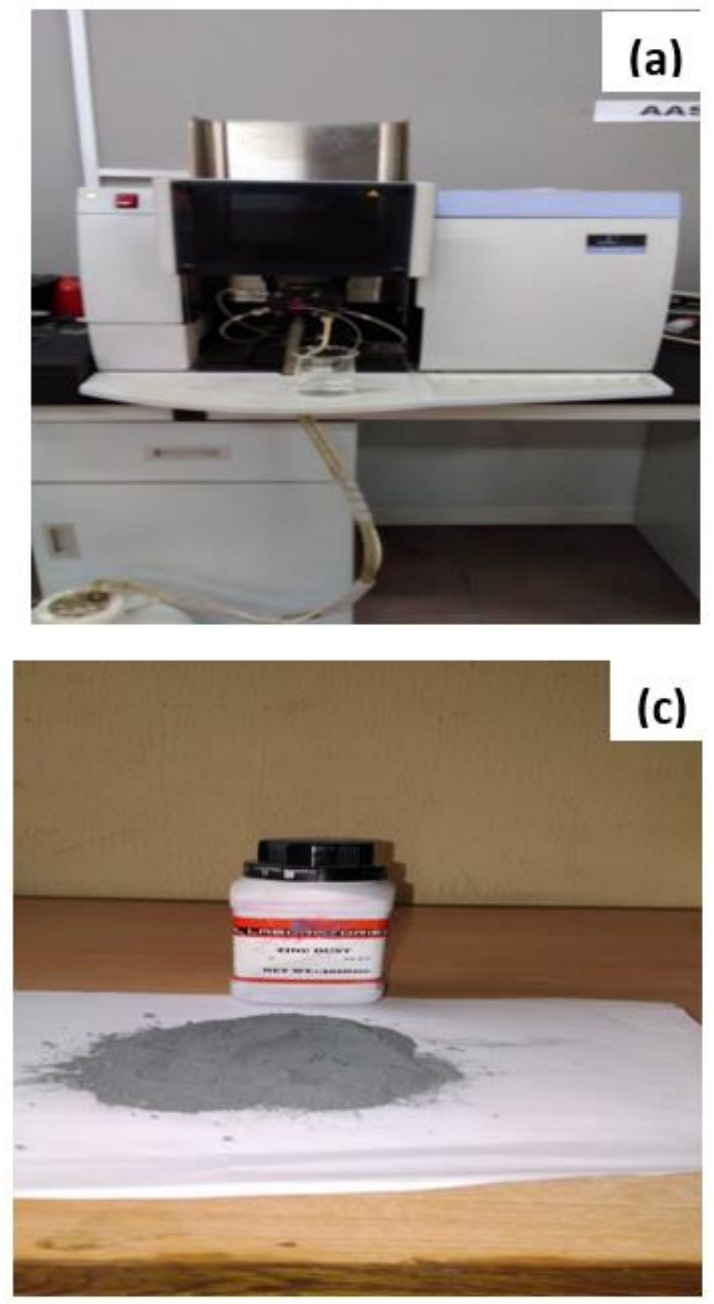
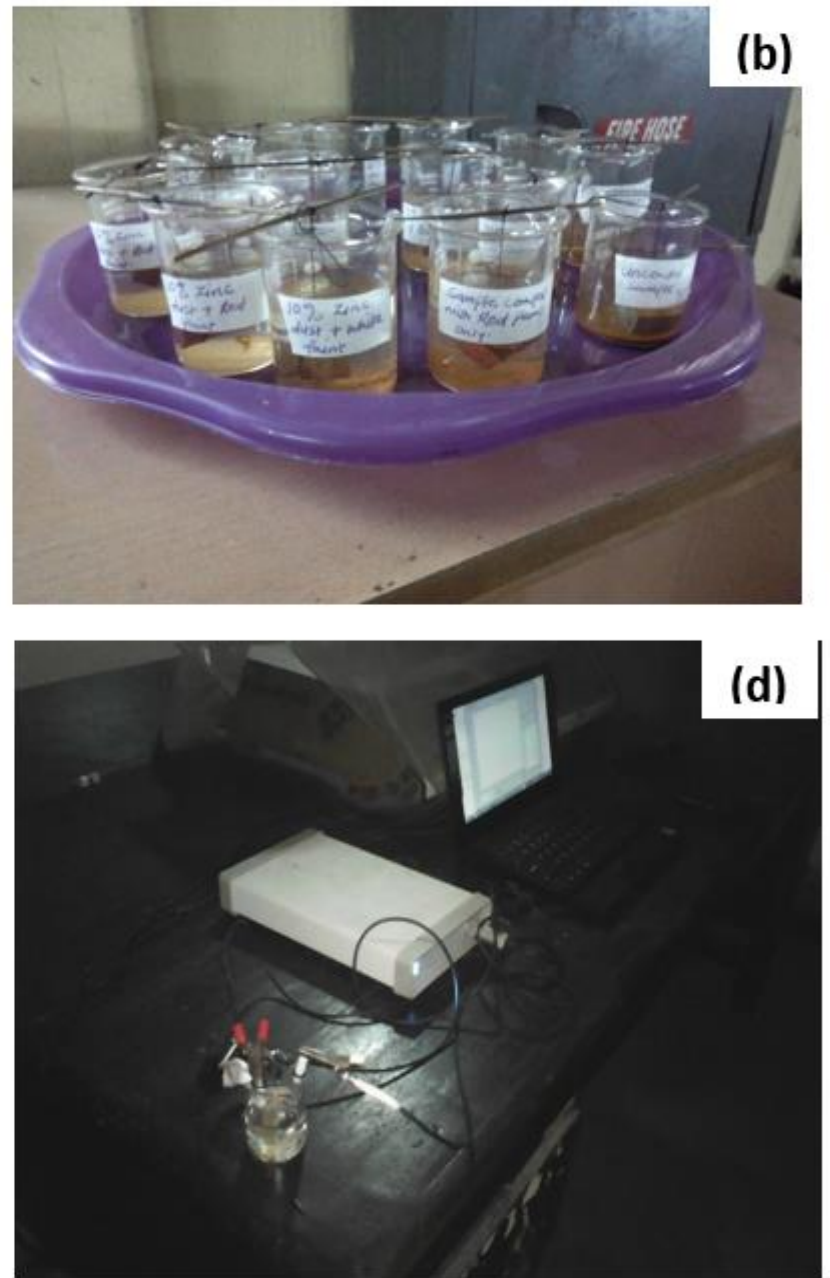

Figure 1:The laboratory set-up and material used a)Atomic Absorption Spectrophotometer, (b) Experimental Setup, (c) Commercial Zinc Powderand (d) Potentiodynamic polarization test set-up

$$
\text { Surface Coverage, } \mathrm{SC}=\frac{\mathrm{CR}_{\mathrm{a}}-\mathrm{CR}_{\mathrm{p}}}{\mathrm{CR}_{\mathrm{a}}}
$$$$
\text { Inhibition Efficiency, IE (\%) }=100 \mathrm{SC}
$$

Where $\mathrm{CR}_{\mathrm{a}}$ and $\mathrm{CR}_{\mathrm{p}}$ are corrosion rates in the absence and presence of the inhibitor, respectively.

\subsection{Potentiodynamic Polarization Technique}

Potentiodynamic polarization test was performed with cylindrical steel electrodes mounted in seawater. The steel electrode was prepared according to ASTM G5997[17]. The studies were performed at $25^{\circ} \mathrm{C}$ ambient temperature with Digi-Ivy 2300 potentiostat and electrode cell containing $200 \mathrm{ml}$ of the acid media (see Figure 1d). Platinum was used as the counter electrode and silver chloride electrode $(\mathrm{Ag} / \mathrm{AgCl})$ was employed as the reference electrode. Potentiodynamic measurement was performed from $-1.5 \mathrm{~V}$ to $+1.5 \mathrm{~V}$ at a scan rate of $0.0015 \mathrm{~V} / \mathrm{s}$ according to ASTM G10289[17]. The corrosion current density $\left(j_{\text {corr }}\right)$ and corrosion potential $\left(E_{\text {corr }}\right)$ were derived from the Tafel plots of potential versus log current.

\subsection{Preparation of Samples for Microstructural Analysis}

The corroded samples were examined with an optical microscope for surface defects. Prior to the microstructural examination, each of the samples was dried in an oven at $30^{\circ} \mathrm{C}$ for 5 minutes $[18,19]$.

\section{RESULTS AND DISCUSSION}

\subsection{Corrosion Rate and Inhibition Efficiency}

In this study, two types of industrial paints were used: Villa Gloss (white paint) and Silka Lux Marine Enamel (red paint). The atomic absorption spectrophotometric analysis of the two paints indicates that the red paint is of higher zinc and calcium constituents than the white paint (see Table 2). The chemical analysis of the corrosive medium used was shown in Table 3. The calcium, salinity and chloride $(\mathrm{mg} / \mathrm{L})$ that are present in corrosive medium are well above the required limit 
for a normal water $[12,13]$. Thus, the seawater used is suitable for this study.

Figures $2-4$ show the variation of the corrosion rate with the time of exposure for the mild steel coated with varied zinc powder addition. Figure 2 indicates that for the control sample and as-procured paints, corrosion rate increased with exposure time. However, it decreased as the percent of zinc powder is increased as shown in Figures 3 and 4. The decrease in the corrosion rate with 5 to $25 \%$ addition of zinc powder is shown in Figures 5 and 6. In general, coating of the mild steel significantly reduces the corrosion rate as compared to the uncoated sample. The initial slow rate of the corrosion at exposure time less 700 hours was due to the formation of a barrier between the substrate and the seawater. Thus, the mild steel is isolated from the aggressive corrosion of the seawater due to the passivation of zinc. Above 1100 hours, passivation can also be noticed with stability in the corrosion rate (Figures 3 \& 4). In this condition, corrosion products, which provides a protective layer has been formed. It can also be deduced from Figures 3 and 4 that for the same exposure time, the red paint performed credibly well than the white paint, as evidence in its lower corrosion rate. The effect of zinc powder addition to the paints on the corrosion rate is less significant when the exposure time exceeded 1500 hours.

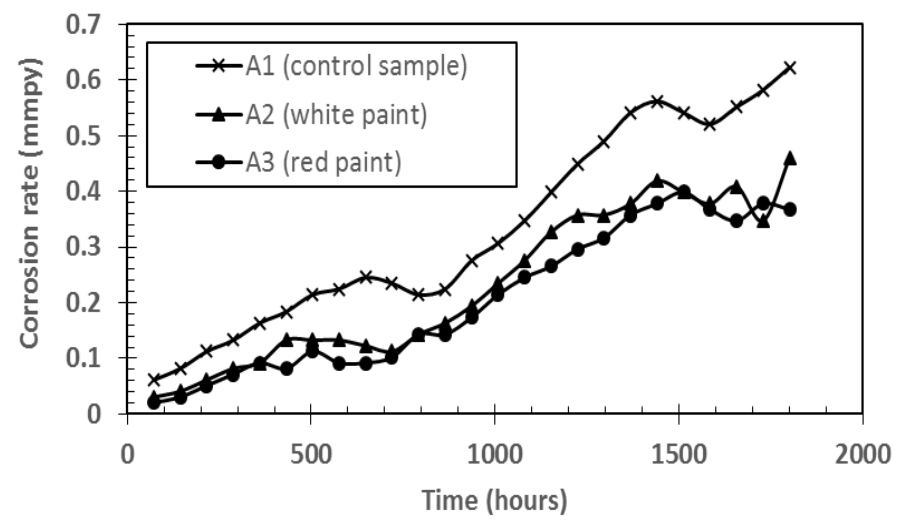

Figure 2: Variation of Corrosion Rate with Exposure Time for Mild Steel without Zn Powder Addition

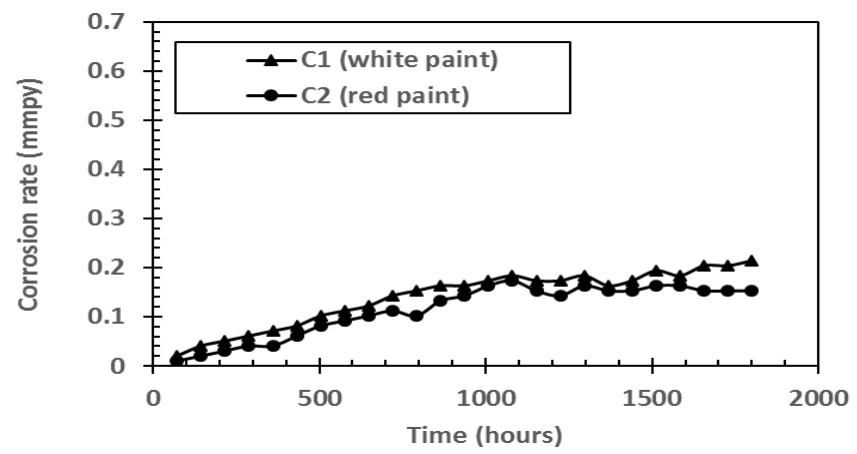

Figure 4: Variation of Corrosion Rate with Exposure Time for Mild Steel with $10 \%$ Zn Powder Addition
The colour change in the corrosive medium over the exposure time help in determining the extent of corrosion control [18]. In this study, the main constituents of the paints are calcium and zinc elements. The colour of the corrosive medium that contain control sample turned completely dark while the coated samples were observed to be colourless and later lightly dark due to the formation iron oxide of the former and $\mathrm{CaCl}_{2}$ and $\mathrm{ZnCl}_{2}$ in the later. Zinc is a sacrificial coating that lessened the corrosion on the mild steel underneath. As it can be noticed in Figures 5 and 6 that the corrosion rate of the samples with 15 to $25 \%$ zinc powder addition stabilises at $0.10 \mathrm{mmpy}$. At optimum zinc powder addition, corrosion rate stabilises due to the conversion of the zinc to zinc trioxocarbonate $\operatorname{IV}\left(\mathrm{ZnCO}_{3}\right)$ during the natural corrosion cycle, as reported by Langill [21].The zinc constituent is converted to zinc oxide ( $\mathrm{ZnO})$ and later to zinc hydroxide depends on the water and air presence in the seawater. Further reaction of $\mathrm{ZnO}$ (white rust)with $\mathrm{CO}_{2}$ (carbon IV oxide) formed $\mathrm{ZnCO}_{3}$, which is acorrosion product that is impermeable to the seawater and very dense layer [21]. Thus, with 15 to 25 $\%$ zinc powder addition, a barrier is formed that prevents further corrosion of mild steel underneath.

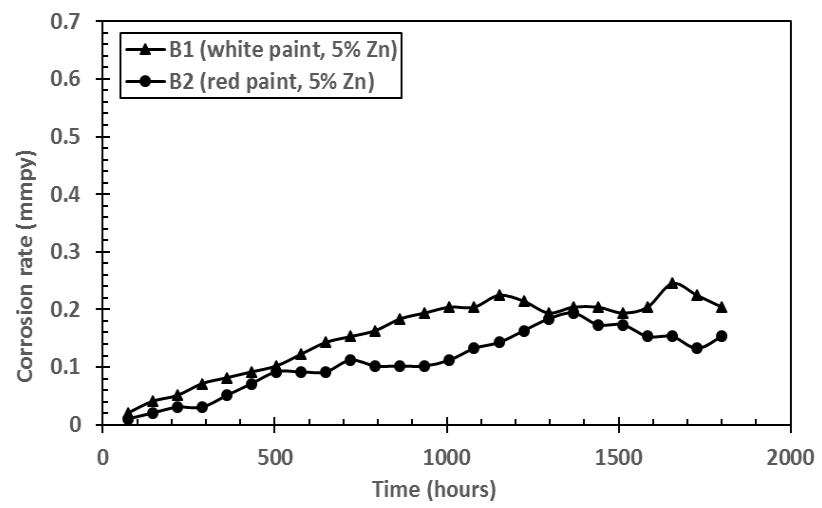

Figure 3: Variation of Corrosion Rate with Exposure Time for Mild Steel with $5 \%$ Zn Powder Addition

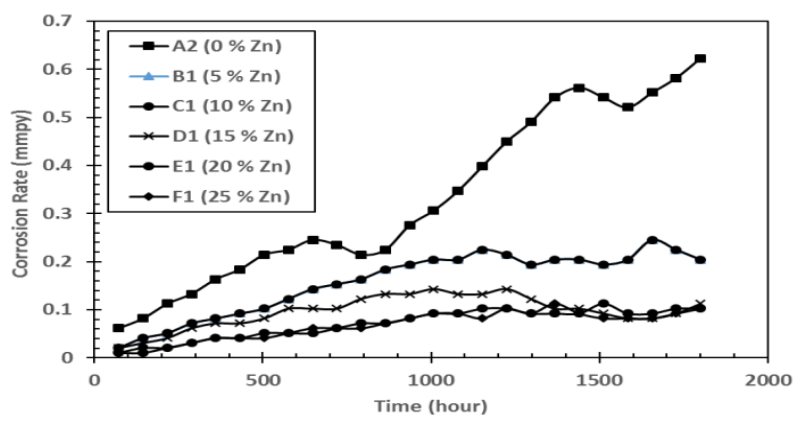

Figure 5: Variation of Corrosion Rate with Exposure Time for Mild Steel Coated in Red with 0-25\% Zn Powder Addition 


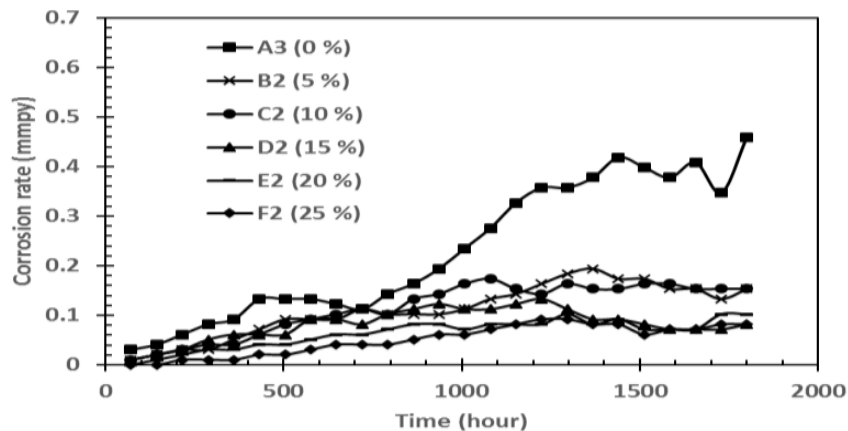

Figure 6: Variation of Corrosion Rate with Exposure Time for Mild Steel Coated in White with 0-25\% Zn Powder Addition

The experimental results indicate that the adhesion of corrosion product of $\mathrm{ZnCO}_{3}$ layer is effective. The protection demonstrated by the layer, however, depends on the $\mathrm{pH}$ of the environment [22]. The corrosion rate changes in an acidic or basic, which may ultimately dissolve the $\mathrm{ZnCO}_{3}$ layer with time. The reaction is more aggressive in acidic medium than basic. In this study, the $\mathrm{pH}$ of the seawater used is 6.47, as shown in Table 4. Thus, it is expected that within 15 to $25 \%$ zinc powder addition and seawater under investigation, the effect of $\mathrm{pH}$ is minimal and erosion of $\mathrm{ZnCO}_{3}$ is low or absent.

Figure 7 shows the dependence of inhibition efficiency on the types of paints and zinc powder addition. The inhibition efficiency was obtained from surface coverage (SC). The inhibition efficiency increased with zinc powder addition. Red paint exhibited higher inhibition efficiency over white paint for the same zinc powder addition due to higher proportion of the zinc present in the as-procured red paint. Above $15 \%$, the effect of zinc powder addition for the two paints on the inhibition efficiency is less significant. This suggests that there is an optimum zinc and calcium mixing composition that is required in a paint to achieve best protective layer, which ultimately reduces and stabilises the corrosion rate. On one hand, zinc and calcium present in the paint formed a barrier between mild steel and the seawater, which increases the inhibition efficiency. On the other hand, the formation of $\mathrm{CaCl}_{2}$ and $\mathrm{ZnCl}_{2}$ tends to reduce the inhibition efficiency. However, saturation of the $\mathrm{CaCl}_{2}$ and $\mathrm{ZnCl}_{2}$ within the seawater stabilised the inhibition efficiency. Figure 8 is the result of total corrosion rate as function of types of paints and zinc powder addition. Stability in the corrosion rate corresponds to zinc powder 15 to 25 $\%$ addition.

\subsection{Potentiodynamic Polarization Technique}

Figure 9 shows the potentiodynamic anodic polarization curves of the mild steel immersed in

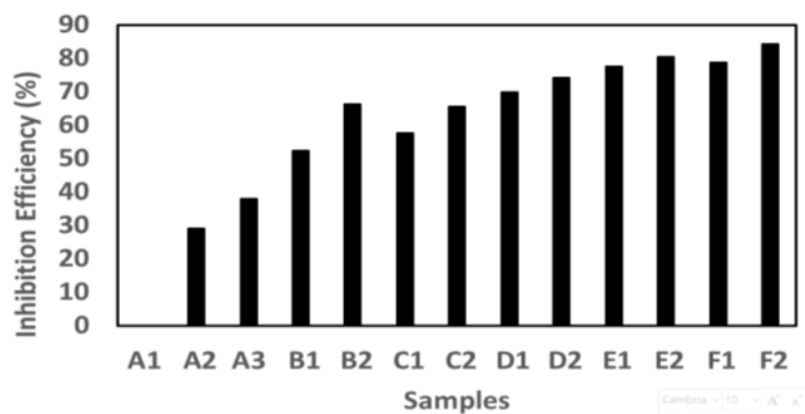

Figure 7: Dependence of Inhibition Efficiency on Sample Processing Condition for Mild Steel Painted in Red and White with 0-25\% Zn Powder Addition

seawater with and without zinc powder addition. The corrosion potential from the figure tends towards the positive direction for all samples except for the control sample. This shows the inhibiting effect of the paints and zinc powder added. The samples with zinc powder addition display active-passive polarization behaviour. Table 5 shows the electrochemical corrosion parameters derived from the potentiodynamic polarisation curves shown in Figure 9. By singling out the corrosion potential and corrosion current for the analysis, the addition of zinc powder causes an increase in corrosion potential and a decrease in corrosion density. Apparently, the ratio of calcium to the zinc in the paints changed with addition of zinc powder, which enhanced the inhibition ability of the paint. For the red paint with $25 \%$ zinc addition has the highest corrosion potential and the lowest corrosion current density, thus, better corrosion resistance. The possible reasons for such behaviour may be addressed as follows. Zinc powder addition increases the formation of amorphous phase within the matrix of the paints thereby enhancing the corrosion resistance property of the mild steel compared to samples with little or no zinc powder addition. This implies that samples coated with $25 \%$ zinc addition has the highest corrosion resistance [23].

Certain condition needs to be met prior to selfpassivation, as suggested by Yang, et al. [24] in formula(V).

$$
E_{e, c} \geq I_{\max }
$$

Where $E_{e, c}$ is the equilibrium potential of depolarizer in the cathodic reducing reaction and $I_{\max }$ is the current density of the depolarizer. From Table 5, it can be observed that Equation 5 has been satisfied. The corrosion potential and corrosion current of the samples are stable for the mild steel coated with $25 \%$ Zinc powder addition at $\cong-0.6505 \mathrm{~V}$ and $5.40 *$ $10^{-8} A$ respectively. 


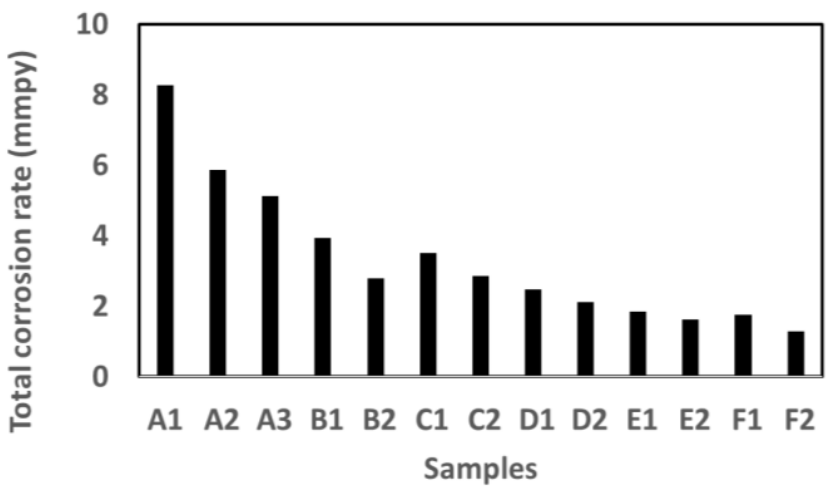

Figure 8: Dependence of Total Corrosion Rate on Sample Processing Condition for Mild Steel Painted in Red and White with 0-25\% Zn Powder Addition

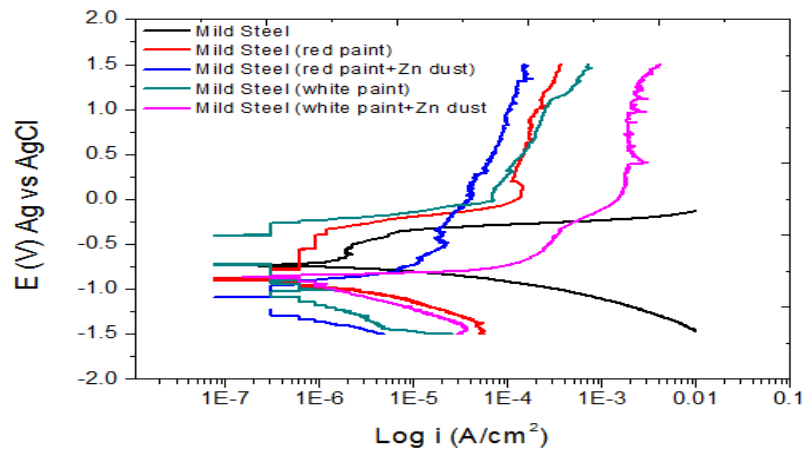

Figure 9: Potentiodynamic Anodic Polarization Plots of Mild Steel Immersed in Seawater with and Without Zn Powder Addition

Table 5: Electrochemical Corrosion Parameters of Mild Steel Immersed in Sea Water with and without Zn Powder Addition

\begin{tabular}{lccc}
\hline Sample & $\begin{array}{c}\left.\text { Corrosion Current ( } \mathrm{I}_{\text {cor }}\right) \\
(\mathrm{A})\end{array}$ & $\begin{array}{c}\text { Corrosion Current } \\
\text { Density }\end{array}$ & $\begin{array}{c}\text { Corrosion Potential } \\
\left(\mathrm{E}_{\text {cor }}\right)(\mathrm{V})\end{array}$ \\
\hline Mild steel & $1.371 \mathrm{E}-06$ & $2.17 \mathrm{E}-06$ & -0.738 \\
Mild steel (white paint) & $5.681 \mathrm{E}-07$ & $9.47 \mathrm{E}-07$ & -0.406 \\
Mild steel (red paint) & $4.921 \mathrm{E}-07$ & $7.81 \mathrm{E}-07$ & -0.501 \\
Mild steel (red paint $+25 \%$ zinc & $5.40 \mathrm{E}-08$ & $9.00 \mathrm{E}-08$ & -0.6505 \\
$\begin{array}{l}\text { powder) } \\
\text { Mild steel (white paint }+25 \% \text { zinc } \\
\text { powder) }\end{array}$ & $5.40 \mathrm{E}-08$ & $1.60 \mathrm{E}-08$ & -0.6001 \\
\hline
\end{tabular}
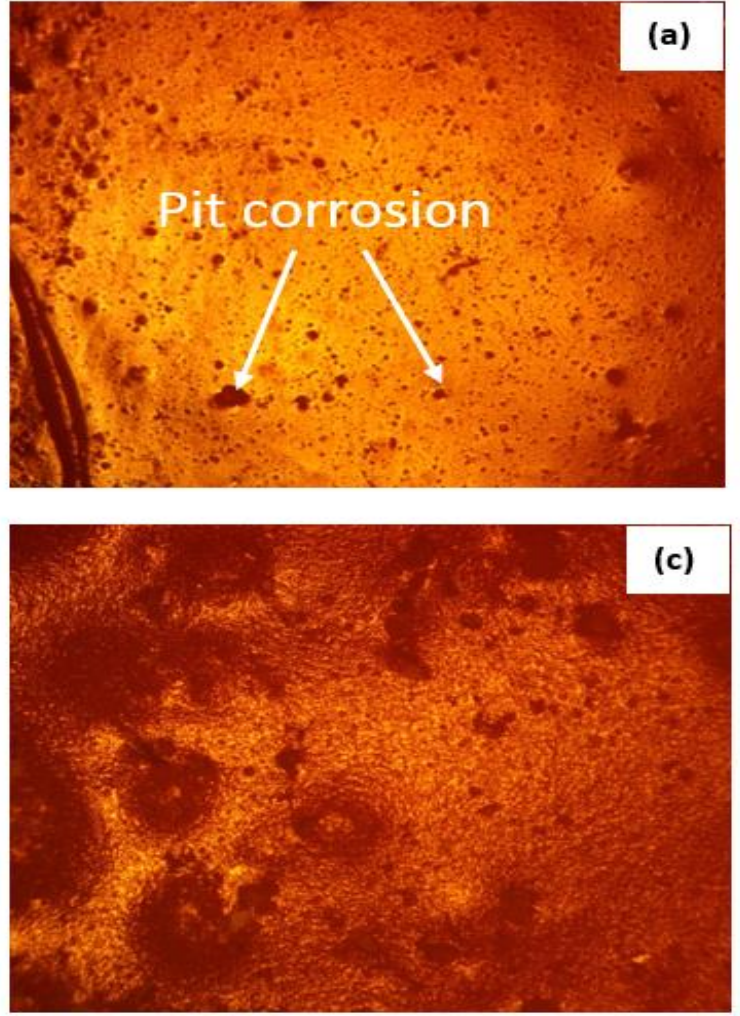
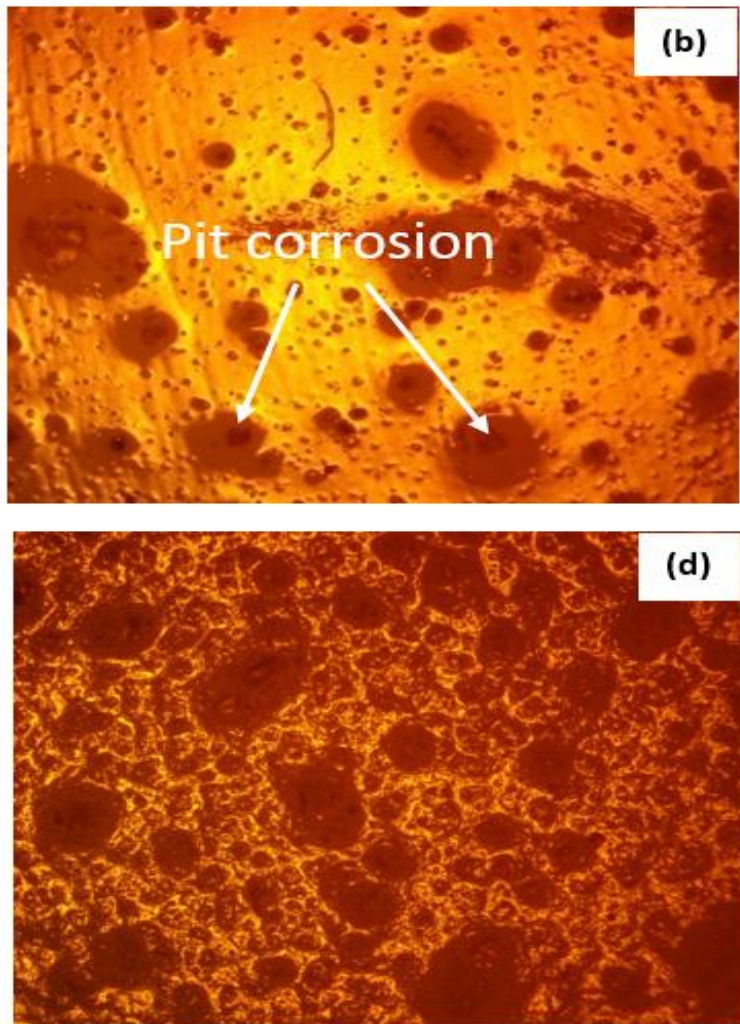

Figure 12: Surface morphology of the corroded samples (a) coated with red paint, (b) coated with white paint, (c) coated with white paint and $10 \%$ zinc powder addition and (d) coated with white paint and $10 \%$ zinc powder addition 


\subsection{Surface Morphology}

Figure 12 (a)-(d) show the surface morphology of some corroded samples. Presence of pit corrosion can be seen. The size of pits are more pronounced in Fig. $12 \mathrm{~b}$ compared to Fig. $12 \mathrm{a}$ due to high inhibition efficiency of red paint. When zinc powder was added, there is a reduction in the amount of the pits visible in Figure 12 (c) and (d). The addition of zinc powder enhances the inhibition efficiency and significantly reduces the corrosion of the samples. It can be observed that samples without zinc addition are more badly corroded. The attack may be due to presence of salinity and chloride in the sea water. The reactions of these substance causes variation in layer thickness of the coating, which lead to localised corrosion characterized by depression or pit formation. Thus, there is a rapid inward penetration of oxygen at the exposed region for the formation iron oxide[15]. Pit formation may also be attributed to ionic migrations, which are influenced by the applied voltage[5]. With the addition of the zinc powder, the process is retarded due to better adhesion of the paints on the surface of the mild steel. Addition of zinc powder does not completely stop the corrosion process. Nerveless, there is an improvement in reduction of corrosion rate when compared with other samples.

\section{CONCLUSION}

This study has shown that:

- Addition of zinc powder to the locally procured Villa Gloss and Silka Lux Marine Enamel paints improved the corrosion resistance of the mild steel.

- The corrosion rate stabilised at approximately 0.10 mmpy when zinc powder added was above $15 \%$. This result was achieved independent of the exposure time.

- Zinc powder addition to both paints was beneficiary to the corrosion potential and corrosion current.

- $\quad$ Surface morphology of the samples revealed pit corrosion characteristics due to the inward penetration of oxygen at the exposed region.

\section{ACKNOWLEDGEMENT}

The authors appreciate the student support of Mr. Edet Andem.

\section{REFERENCES}

[1] Tator, K. B. and Tator, K. T. A, "Coating Deterioration," Vol. 5B, K. B. Tator, Ed. USA: ASM
International, pp. 463-473, 2015.

[2] Hudson, R. Coating for the Protection of Structural Steelwork. UK: DTI, 2000.

[3] Pastorek, F., Borko, K., Fintova, S. K. D, and Hadzima, B. "Effect of Surface Pretreatment on Quality and Electrochemical Corrosion Properties of Manganese," Coatings, Vol. 6, No. 46, pp. 1-9, 2016.

[4] Zheludkevich, M. L.; Serra, R.; Montemor, M. F.; Salvador, I. M. M. and Ferreira, M. G. S. "Corrosion Protective Properties of Nanostructured Sol - Gel Hybrid Coatings to AA2024-T3," Surf. Coat. Technol., Vol. 200, Pp. 3084-3094, 2006.

[5] Popoola, A. P. I., Olorunniwo, O. E.and Ige, 0. "Corrosion Resistance Through the Application of Anti-Corrosion Coatings," Developments in Corrosion, Vol. 5, Pp. 241-270, 2014.

[6] Armelin, E;, Alemán, C. and Iribarren, J. I. "Progress in Organic Coatings Anti-Corrosion Performances of Epoxy Coatings Modified with Polyaniline: A Comparison Between the Emeraldine Base and Salt Forms," Prog. Org. Coatings, Vol. 65, Pp. 88-93, 2009.

[7] Armelin, E.; Pla, R.; Liesa, F.; Ramis, X.and Alema, C. "Corrosion Protection with Polyaniline and Polypyrrole as Anticorrosive Additives for Epoxy Paint," Corros. Sci., Vol. 50, Pp. 721-728, 2008.

[8] Abdel-samad, A. A. and Zaki, M., "Influence of Paint on Steel Corrosion for Marine Applications," J. Surf. Eng. Mater. Adv. Technol., Vol. 4, Pp. 189-195, 2014.

[9] Fayomi, O. S. I. and Popoola, A. P. I. "An Investigation of the Properties of Zn Coated Mild Steel," Int. J. Electrochem. Sci, vol. 7, pp. 6555 6570, 2012.

[10] Kaiming, W., Baohua, C., Jiongshen, C., Hanguang, F., Yinghua, L.and Yongping, L. Effect of Molybdenum on the Microstructure and Properties of Stainless Steel Coatings by Laser Cladding. Applied Science, Vol. 7; No. 1065, Pp 2-15, 2017.

[11] Durodola, B. M; Olugbuyiro, J. A. O.; Moshood, S. A; Fayomi, O. S., and Popoola, A. P. I, "Study of Influence of Zinc Plated Mild Steel Deterioration in Seawater Environment," Int. J. Electrochem. Sci, Vol. 6, Pp. 5605 - 5616, 2011.

[12] Nigerian Industrial Standard, "Nigerian Standard for Drinking Water Quality", NIS554:URL:https://www.unicef.org/nigeria/ng_p ublications_Nigerian_Standard_for__ Drinking Water_ Quality.pdf, Accessed on December 21, 2017

[13] World Health Organisation (WHO), "Nutrients in Drinking Water," Geneva, 2005. 
[14] Esmaeely, S. N.; Choi, Y.S.; Young, D. and Nešić, S., "Effect of Calcium on the Formation and Protectiveness of Iron Carbonate Layer in $\mathrm{CO}_{2}$ Corrosion", Corrosion. 69(9): Pp 912- 920, 2013.

[15] Fauchais, P. and Vardelle, A, "Thermal Sprayed Coatings Used Against Corrosion and Corrosive Wear". Adv. Plasma Spray Appl., Pp. 3-39, 2012.

[16] Ikechukwu, A. S. and Ugochukwu, N. H, "Studies on Corrosion Characteristics of Carbon Steel Exposed to $\mathrm{Na}_{2} \mathrm{CO}_{3}, \mathrm{Na}_{2} \mathrm{SO}_{4}$ and $\mathrm{NaCl}$ Solutions of Different Concentrations .," Int. J. Eng. Sci., Vol. 3, No. 10, Pp. 48-60, 2014.

[17] Li, R;, Li, Z;, Huang, J;, Zhang, P, and Zhu, Y. "Effect of Ni-to-Fe Ratio on Structure and Properties of Ni-Fe-B-Si-Nb Coatings Fabricated by Laser Processing," Appl. Surf. Sci., Vol. 257, No. 8, Pp. 3554-3557, 2011.

[18] Umunakwe, R., Olaleye, D. J., Oyetunji, A., Okoye, 0. C. and Umunakwe, I. J. Assessment of Some Mechanical Properties and Microstructure of Particulate Periwinkle Shell-Aluminium 6063 Metal Matrix Composite Produced by Two-step Casting. Nigerian Journal of Technology, Vol. 36 (2), pp. 421-427, 2017
[19] Adeosun, S. O.; Oyetunji, A. and Akpan, E. I. . Strength and Ductility of Forged 1200 Aluminum Alloy Reinforced With Steel Particles. Nigerian Journal of Technology, Vol. 34, No. 1, Pp. 710-715, 2015

[20] Federal Aviation Administration. "Corrosion Control". United States of America, Pp. 23-56, 2005.

[21] Langill, T. J. "Painting Over Hot Dip Galvanised Steel," Mater. Sci., Vol. 31, No. 5, Pp. 39-42, 1992.

[22] Mahdavian, M. and Attar, M. M. "Electrochemical Behaviour of some Transition Metal Acetylacetonate Complexes as Corrosion Inhibitors for Mild Steel," Corrosion Science. Vol. 51 (2), Pp. 409-414, 2009.

[23] Yue, M. T.; Hu, Q. W.; Mei, Z., and Man, H.C. "Laser Cladding of Stainless Steel on Magnesium ZK60rSiC Composite," Mater. Lett., Vol. 47, Pp. 165-170, 2001.

[24] Yang, X. Y;, Peng, X; , Chen, J., and Wang, F. "Effect of a Small Increase in the Ni Content on the Properties of a Laser Surface Clad Fe-Based Alloy," Appl. Surf. Sci., Vol. 253, No. 9, Pp. 4420-4426, 2007 